\title{
Voz, Corpo, Linguagem
}

Luiz Augusto de Paula Souza (Tuto)

ão muitos e habituais os caminhos pelos quais a dimensão física do corpo tem sido apartada de sua dimensão simbólica; caminhos traçados por uma extensa tradição dualista. A separação entre corpo e alma (psique) talvez seja a principal matriz a estimular tal dicotomia.

Perpetuado sob o signo do platonismo, aquele dualismo atravessa os tempos, atualizando-se no cartesianismo e em outras vertentes neoplatônicas, tanto idealistas, quanto em certos materialismos. Se no idealismo supõe-se a hegemonia da "alma" (inata ou divina) sobre o corpo - suporte ou forma na qual o conteúdo se inscreve; no, digamos assim, materialismo organicista a fórmula se inverte: o orgânico determina o psíquico; este último é reduzido a, por exemplo, efeito de reações físico-químicas e de engramas cerebrais. O dualismo, neste caso, opera e se resolve pela separação categórica entre produtor (corpo físico) e produto (no caso, o psiquismo) - laminação biologizante do humano.

Duas fórmulas distintas, sem dúvida, mas com pelo menos um efeito (ou perigo) decisivo e comum: a "essencialização" polarizada da exis- tência, num dos pólos o predomínio hegemônico do biológico, no outro, a supremacia da alma. Deste limitado esquema binário não existem saídas, fica-se preso à fixidez de um maniqueísmo e de uma oposição paralisante, pois, como dizia Deleuze (1992), não há vida nos extremos, ao contrário, a vida engendra-se e transita pelo meio, criando os termos que, eventualmente, virão a se estratificar.

Se for assim, não são os termos que constroem as relações, ao contrário, são estas que os (re)criam, disponibilizando-os para que, com eles, sejam elaborados sentidos capazes de ganhar expressão. Deleuze e Guattari (1996) criam, a partir de noções emprestadas da química, dois conceitos filosóficos que podem ajudar na seqüência da reflexão que se acaba de iniciar, são eles: o molar e o molecular. Eles designam os planos constituintes do real, respectivamente, sua dimensão formalizada, organizada; e sua dimensão afetiva ou intensiva, não/organizada, processual e diferencial. O molar e o molecular são, a um só tempo, indissociáveis e irredutíveis, não há uma linha molar sem uma molecular que the balize e vice-versa; elas estão sempre emaranhadas, mas não se confundem, ou seja,

Luiz Augusto de Paula Souza (Tuto) é fonoaudiólogo e professor titular da Faculdade e do Programa de Estudos Pós-Graduados em Fonoaudiologia da PUC-SP. 
“os mesmos elementos existentes nos fluxos, nos estratos, nos agenciamentos, podem organizar-se segundo um modelo molar ou segundo um modelo molecular. A ordem molar corresponde às estratificações que delimitam objetos, sujeitos, representações e seus sistemas de referência. A ordem molecular, ao contrário, é a dos fluxos, dos devires, das transições de fases, das intensidades" (Guattari \& Rolnik, 2005, p. 385-6).

Além disso, uma linha não pára de interferir na outra, as formas constituídas ou estratos torcem e pressionam a linha molecular e esta, por sua vez, produz fissuras na linha molar, engendrando aí vetores de transformação, com suas inéditas velocidades e processualidades. Esses processos de diferenciação são chamados por Deleuze e Guattari (op. cit.) de linhas de fuga. Nos estratos sempre há algo - por mais ínfimo que seja - que foge, que escapa à fixação numa forma dada, abrindo-se à alteridade (relação ao outro), de onde vem a capacidade de se transformar, de ativar a potência de (re)singularização.

Neste sentido, a passagem de composições de forças (intensidades) do plano molecular para o molar é o que se pode chamar de acontecimento, ou seja, algo que existia como uma potência, como um devir, atualiza-se sob uma nova forma, expressando-se no plano molar em dois eixos interdependentes: o visível e o dizível, nos quais impõe, em alguma medida, sua diferença ou sua potência de diferenciação.

Pois bem, com esses operadores, como pensar a relação orgânico/simbólico de outra perspectiva, que não a do maniqueísmo dualista?

$\mathrm{Na}$ posição que assumimos, se se permanecer restrito ao plano molar, as variaçōes possíveis na fórmula dualista deixam escapar o essencial, pois estão calcadas na oposição orgânico/simbólico. Explico. O dualismo para vingar precisa apoiar-se em, pelo menos, duas premissas: 1. a unidade individual do sujeito; 2 . a dupla natureza do humano, ou seja, a unidade individual fundada por duas instâncias inconciliáveis - corpo e alma.

Ora, se o real é feito de processos de diferenciação (linha molecular) e cortes ou paradas de processo (linha molar), não há unidade possível, a processualidade não cessa de nos fazer um sempre-outro, um vir a ser constante; as formas - subjetivas e objetivas - que inventamos são modelações e desacelerações dos processos vitais, aliás absolutamente necessárias à vida, em especial à vida humana, pois constituem as formas nas quais nos reconhecemos. Significa dizer que sem elas não existiria a forma homem, nem conhecimentos, sociedades, etc.

Porém, igualmente indispensáveis são as desestabilizaçôes e transformaçôes a que estamos sujeitos - em maior ou menor grau, dependendo da época e das circunstâncias individuais e coletivas -, sem as quais permaneceríamos idênticos a nós mesmos, numa eterna reedição do mesmo. Se apenas reedita-se uma suposta condição ou essência original, não há criação possível e, por conseqüência, também não pode haver ciência, arte, filosofia...

$\mathrm{Na}$ verdade, é a vida, ela mesma, que perderia suas condições de possibilidade, pois até os ciclos vitais (nascimento, vida e morte) seriam inviáveis, na medida em que também eles dependem de mudanças substantivas, tanto no que chamamos "biológico", quanto - no caso do humano - no que designamos por simbólico: não temos o mesmo corpo físico, nem as mesmas idéias, sensações, sentimentos e desejos que tínhamos há tempos atrás.

O dualismo psicofísico, assim como a idéia de essência fundante (seja ela divina ou racional/biológica) e de sujeito unitário, entre outras ilusões, são um logro que o humano se impôs como paliativo, anestésico para suportar a dor da finitude, da provisoriedade das formas nas quais nos reconhecemos; também para suportar o medo do desconhecido, do imprevisível, do acaso do encontro com o outro.

O dualismo releva, então e em última instância, de um medo aterrador da alteridade mas, 
ao mesmo tempo, de uma impossibilidade de viver fora de seu escopo. Senão vejamos. Do mesmo modo que os símbolos carregam e veiculam o corpo, eles se encarnam no corpo físico; o corpo os contrai e deles se apropria anatômica, fisiológica e metabolicamente, mas não sem dor, sem estranhamento, sem desassossego; daí o medo que sentimos todas as vezes em que nos damos conta de que algo se transforma em nós, é como se o chão faltasse, porque esmaece a suposta terra firma de nossas convicçôes, sentimentos, valores... É, sem dúvida, a virulência das intensidades (linha molecular) que provoca o terror: medo de desorganizar-se, de sucumbir inevitavelmente; impossibilidade de ver que os processos de diferenciação não são, necessariamente, o anúncio do fim, mas às vezes o seu contrário: expansão do "mundo" para além das formas dadas, naquilo que a consciência (serva do que é familiar, conhecido) geralmente não pode alcançar.

De qualquer forma, em que pese nossos hábitos, tradições e valores mais agarrados ao que supomos conhecer e controlar, a condição humana continuará, em alguma medida, a engendrar-se, desmanchar-se e a re-germinar; ela se transmuta, retornando sempre como diferença na carne e nos signos. Diferença que faz diferença e não apenas nuances formais; linhas de resistência aos saberes, ilusões e poderes totalitários, totalizantes e que naturalizam nossa percepção das coisas e dos processos.

Mas o que a voz e a linguagem têm a ver com a recusa do dualismo psicofísico e com a afirmação das dimensões orgânica e simbólica como faces de um mesmo processo?

A intenção aqui não é a da "última palavra”, isto é, daquela pretensamente mais correta, que ousaria supor ser definitiva ou totalizante. Bem ao contrário, quem, de algum modo, está atento às experiências e fenômenos nos quais o homem toma parte, sabe ou intui a impossibilidade e até o ridículo de uma tal pretensão. Analisar a relação entre voz e linguagem é entrar numa arena polêmica, pois exige trânsito em zonas de fronteira entre saberes e ló- gicas diferentes, o que implica manejar concepções e abordagens distintas, às vezes mesmo incompatíveis.

Os termos desta relação têm sido pensados em várias esferas do conhecimento - muito já se falou da voz e da linguagem, tanto na ciência, quanto na arte e na filosofia. Há vários planos de intersecção entre elas, mas no momento vamos operar com apenas um recorte, entre vários possíveis. Abordaremos, principalmente, relações entre fala e sentido.

O emprego da língua na fala é modalizado e singularizado pelos falantes por meio de um jogo complexo de motivaçôes (inclusive inconscientes) e intençóes - mutáveis conforme as situações e estados das pessoas -, que se expressam menos no que dizem do que no como dizem. Isto refere-se, na classificação lingüística, ao nível prosódico: altura, intensidade, ressonância, inflexão (principalmente), etc., compõem, digamos assim, a voz da fala.

Sob essa óptica, linguagem e voz estão pensadas no plano molar, uma vez que tal leitura diz respeito a descrição de formas de expressão e de relação constituídas. Processo que, na aparência, é objetivo e no qual fala e voz gozam de autonomia. Em outras palavras, cada $o$ que tem, num dado contexto, um como correspondente, mas estes não se confundem.

No entanto, e é precisamente isto que mais interessa aqui, o plano do sentido "engrossa o caldo do problema”, mostrando que ele não é tão simples quanto pode parecer à primeira vista. Para começar, é preciso esclarecer que sentido será tomado numa acepção bastante precisa, enquanto resultante das maneiras pelas quais são sentidas/vividas, significadas e expressas as experiências. Portanto, de como nos comunicamos, cada um consigo mesmo e com o outro.

Comunicação entendida não como recebimento e emissão de mensagens concebidas e codificadas pelo pensamento, do qual a linguagem seria um veículo de expressão. Ao contrário, comunicação pensada como função e potência da linguagem, no sentido de um desejo inelutável, aquele de se comunicar com um 
outro e de por este ser acolhido (Dolto, 1999), pois esta é uma condição incontornável para a emergência e estruturação do humano.

Nesse sentido, a linguagem tem a ver com a processualidade especificamente humana, aquela que é decidida como jogo simbólico diferencial ou produção de sentido e que engendra diferenças nos processos de singularização e de constituição subjetiva de pessoas e grupos, contornando as dimensões orgânica e simbólica do funcionamento do corpo humano.

“O quê pode um corpo?", pergunta Spinoza (1989). A resposta do filósofo é simples e direta: afetar e ser afetado. Esta é a potência própria a um corpo vivo. Ora, qualquer vivo afeta e é afetado, e isto define o modo como age, reage, sente e "lida" com seus processos vitais. Se assim é, a questão passa a ser: como os afetos esculpem, criam um corpo?

Os vivos são afetados de modos diferentes e diferenciais por muitas coisas. Um carrapato, brinca Deleuze (1992), vive de poucos afetos: a luz, o calor e o cheiro de sangue o afetam, e ele afeta animais de sangue quente. $O$ carrapato nasce e fica inerte até que uma combinação de alguns ou de todos esses elementos o afetem, disparando sua trajetória de atividade, ao cabo da qual se encerra seu ciclo de vida.

No homem é diferente, os afetos são múltiplos, ilimitados e muito mais complexos, porque compostos por emaranhados de forças e elementos, das físicas às psíquicas e culturais. Isto talvez tenha se dado - como quer a biologia pelo lugar do homem na escala zoológica, em termos de complexidade, como também pelo fato da espécie humana ser menos adaptada e codificada geneticamente; o que se supõe ter gerado, por força do acaso e de contingências várias, uma série de condições e necessidades singulares a nossa espécie, definindo uma versatilidade, primeiramente biológica e depois social e semiótica sem precedentes.

Esta condição singular da espécie humana faz com que seus afetos (ou parte deles) sejam processados e elaborados para além de sua ocorrência imediata, pois a espécie dispóe de um sofisticado repertório biológico (neuronal, anatômico e fisiológico) que lhe faculta afetar e ser afetado, inclusive pelos da sua espécie, para além do plano sensório/motor.

Tal complexidade do animal humano permite que ele conquiste o delírio, a fabulação, a razão..., que ele produza e simbolize imagens de si e do mundo, compostas a partir dos afetos, num imaginário que, singularizado pelo sujeito, deriva das experiências coletivas ou daquilo que se passa no encontro com o outro.

Tudo isso acontece processualmente, por meio de experimentaçóes capazes de enredar orgânico e simbólico; individual e coletivo, em composições múltiplas e multivalentes de afetos, convertendo-os em signos, que a voz encarna na produção da fala, da "musica da fala". Em outros termos, aquilo que se passa entre os corpos humanos (em suas faces simultaneamente materiais e imateriais) é condição de possibilidade do sentido, é o que o faz acontecimento.

Este funcionamento afetivo ou processo molecular, que agencia fluxos os mais diversos, é a matéria prima da linguagem, da qual são extraídos as formas de expressão e as formas de conteúdo (Deleuze, 1987). Por esse ângulo, a linguagem poderia ser dita também como funcionamento de funcionamento, isto é, como funcionamento no qual são criadas e decididas as formas de expressão e de conteúdo do funcionamento afetivo.

No âmbito da linguagem, esta posição exige um deslocamento em relação ao campo representacional, no qual a linguagem limita-se a reapresentar o mundo: palavras (significantes) como formas convencionais das coisas e dos fenômenos (significados). Este deslocamento põe em evidência a dimensão intensiva ou molecular da linguagem, aquela que a faz integrar a criação e a elaboração dos processos de existencialização. A linguagem constituindo (ainda que não exclusivamente) o real e não apenas duplicando-o nas representaçōes. ${ }^{1}$

Se for assim, linguagem e voz se misturam, é possível ouvi-las nos acordes de sentidos que engendram e nas sensações que mobilizam 
no corpo (agora, simultaneamente, orgânico e simbólico), de quem fala e de quem ouve. Isso ocorre porque ambas são corpo, efeitos dos afetos, da capacidade de afetar e de ser afetado por outros corpos, por isso aptos à veicular, à traduzir e à elaborar nossas sensaçôes.

A linguagem, quando é criação e elaboração (em oposição a sua função estritamente representativa), enlaça-se com a voz de maneira quase indiscernível. Elas constituem um processo comum que é o de, ao mesmo tempo, potencializar a inventividade oriunda dos planos intensivos e criar formas enunciativas. A literatura, por exemplo, trata assim a linguagem e incorpora, mesmo na escrita, os sentidos e a musicalidade que a voz traz à baila. $\mathrm{O}$ teatro articula uma série de recursos - literários, vocais, corporais, musicais, etc., capazes, muitas vezes, de integrar corpo, voz e fala num intrincado jogo de sentidos. A música (no caso, a música cantada), também pode promover este encontro e levá-lo às últimas consequiências, é inegável a existência de combinações de música, letra e interpretação que nos afetam de tal modo que seria estranho não dizer que esta relação é, ela mesma e no limite, linguagem. ${ }^{2}$

Em síntese, são duas maneiras de ver, uma articulando, no plano molar, voz, corpo e linguagem: instâncias que se tocam mas não se confundem; e uma outra, que é trama entre planos (afetivos e representativos), que desdobra, do/no corpo, voz e palavra, sentido e forma verbal, compondo espécies de sinfonias - sempre inacabadas e por esta razão mutáveis - de ruídos, sons, silêncios, ritmos, andamentos, acontecimentos e interpretações.

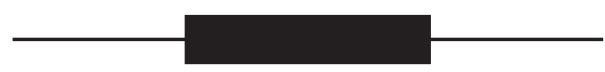

\section{Referências bibliográficas}

DELEUZE, Gilles. Conversaçôes. Rio de Janeiro: Editora 34 Letras, 1992.

Foucault. Lisboa: Veja, 1987.

DELEUZE, Gilles \& GUATTARI, Felix. Mil Platôs. Rio de Janeiro: Editora 34, 1998. Vol. 3.

DOLTO, Françoise. Tudo é linguagem. São Paulo: Martins Fontes, 1999.

ESPINOZA, Baruch. Ética. São Paulo: Abril, 1989. Col. “Os Pensadores”.

GUATTARI, Felix \& ROLNIK, Suely. Micropolítica, cartografias do desejo. 7a. ed. Petrópolis: Vozes, 2005.

1 Há um bom tempo atrás, tratei mais detalhadamente este assunto em "Linguagem, Representação e Alteridade", Cadernos de Subjetividade, Vol. 2, n. 2, São Paulo, Núcleo de Estudos da Subjetividade, PUC-SP, 1995.

2 É claro que nem todas as obras literárias, teatrais ou musicais conseguem efetuar esta fusão e, também, é claro que nem sempre temos ouvidos para escutar aquilo que nos oferecem como criação e/ou recriação. Além disso, é importante lembrar que não é só na literatura ou na música que o contato com o plano intensivo das experiências se dá; eles ocorrem nas artes plásticas, na dança, na ciência, na filosofia e também, porque não, em certas circunstâncias da vida cotidiana. Destaquei a arte porque ali este fenômeno é mais evidente, "ilustrando" os comentários com perspectivas que falam mais de perto da voz na linguagem e da voz como linguagem. 